\title{
A INCONSTITUCIONALIDADE DA COBRANÇA “POR DENTRO” DO ICMS
}

\author{
Iásin Schäffer Stahlhöfer ${ }^{1}$ \\ João Fernando Fank ${ }^{2}$ \\ Marcelo Carlos Zampieri ${ }^{3}$
}

\begin{abstract}
Resumo
Esse trabalho tem por objetivo analisar dois casos concretos com fundamentos semelhantes: o questionamento da constitucionalidade da utilização da base de cálculo "por dentro" do ICMS. Não obstante os desfechos e desdobramentos dos casos em estudo, concluindo pela legalidade do método, argui-se a sua inconstitucionalidade neste artigo. Considera-se também a emenda constitucional de $n^{\circ} 33$ de 11 de dezembro de 2001 que, na esteira dos entendimentos jurisprudenciais cristalizados nos casosparadigma em estudo neste artigo, visava a legitimar em sede constitucional a deletéria prática, com o objetivo de extinguir os reiterados questionamentos judiciais. Entretanto, como será demonstrado, o poder de reforma foi mal-empregado, levando à inserção de norma teratológica no âmbito da Constituição Federal de 1988, conflitante com a principiologia da sistemática tributária por ela adotada e com as limitações instituídas ao poder de tributar.
\end{abstract}

Palavras-chave: ICMS. Cobrança "por dentro". Constitucionalidade.

\section{THE UNCONSTITUTIONALITY OF "POR DENTRO" (SELF CONTAINED) COLLECTION OF ICMS (TAX OVER THE CIRCULATION OF GOODS AND SERVICES)}

\begin{abstract}
This work intents to analyze two concrete cases with similar foundations: questioning of the constitutionality of the "internal" taxation for the Imposto sobre Circulação de Mercadorias e Serviços. Notwithstanding the fate of both cases in study, finding the method constitutional, herein we argue its non-constitutionality. The Constitutional Amendment $n^{\text {o }} 33$, from December $11^{\text {th }}$, 2001, is also considered, as it, following the tread presented by the jurisprudence represented in this article by the paradigmatic cases under study, sought to legitimate on a constitutional level the detrimental taxation method, so as to extinguish the reiterated judicial interpellations against it. However, as it will be demonstrated, the reforming power was misused, leading to the inclusion of a teratologic rule in the Federal Constitution of 1988 , due to its conflicting with the principles of the tributary system and the limitations instituted for the taxation power.
\end{abstract}

Keywords: ICMS. Self contained taxation. Constitutionality.

\footnotetext{
1 Autor. Atualmente é graduando do $10^{\circ}$ semestre do Curso de Ciências Jurídicas e Sociais da Universidade Federal de Santa Maria. Atuante em projetos de pesquisa e de extensão com bolsa provida pela própria Instituição. Participante do Grupo de Pesquisa Direito da Sociobiodiversidade sob coordenação do Prof. Dr. Luiz Ernani Bonesso de Araujo e Prof. Ms. Jerônimo Siqueira Tybusch. EditorAssistente da Revista Eletrônica do Curso de Direito da UFSM. Estagia no Lutz Coelho Advogados Associados. Email: iasindm@gmail.com

${ }^{2}$ Autor. Atualmente é graduando do $10^{\circ}$ semestre do Curso de Direito da Universidade Federal de Santa Maria. Atuante em projetos de pesquisa e de extensão com bolsa provida pela própria Instituição. Participante do Grupo de Pesquisa Direito da Sociobiodiversidade sob coordenação do Prof. Dr. Luiz Ernani Bonesso de Araujo e Prof. Ms. Jerônimo Siqueira Tybusch. Editor-Assistente da Revista Eletrônica do Curso de Direito da UFSM. Email: jffank@ hotmail.com

3 Orientador. Possui graduação em Direito pela Universidade Federal de Santa Maria (1995), Especialização em Direito Público pelo Centro Universitário Franciscano (1997) e Mestrado em Direito pela Universidade de Santa Cruz do Sul (2002). Atualmente é Professor Assistente da Universidade Federal de Santa Maria, Professor Assistente do Centro Universitário Franciscano e Professor da Universidade Regional Integrada do Alto Uruguai e das Missões. Tem experiência na área de Direito, com ênfase em Direito Privado. Atuando principalmente com Direito Comercial. Email: mzampieri@abbz.com.br
} 


\section{INTRODUÇÃO}

A cobrança de do Imposto sobre Circulação de Mercadorias e Serviços - ICMS - vem, há muitos anos, sendo realizada de forma que a alíquota integre a base de cálculo do próprio imposto. Na prática temos um aumento por via oblíqua no valor a ser pago. A título exemplificativo, utilizaremos uma fatura de energia elétrica: para um consumo de cem reais, o esperado, considerando uma alíquota de $25 \%$, é que se pague cento e vinte e cinco reais ao todo. Contudo, o método citado faz com que os $25 \%$ do imposto integrem a base de cálculo, logo, o consumidor paga cerca de cento e trinta e um reais e vinte e cinco centavos. Note-se que, de uma ardilosa forma, o consumidor acaba por pagar $31,25 \%$ sobre o consumo, e não os $25 \%$ estatuídos.

O presente trabalho, utilizando o método dialético, busca o contraponto de posições entre casos concretos, doutrinadores e texto legal com o escopo de questionar a constitucionalidade dessa modalidade de cobrança de imposto denominada "por dentro". Para tanto, apresentam-se conceitos doutrinários, posicionamento do Supremo Tribunal Federal e o histórico das normas legais pertinentes à questão.

\section{Imposto sobre Circulação de Mercadorias e Serviços e a cobrança "por dentro"}

O Imposto sobre Circulação de Mercadorias e Serviços - ICMS - apresentado pela Constituição Federal no art. 155, II, é um tributo de competência dos Estados e do Distrito Federal; assim estatui o citado artigo:

Art. 155. Compete aos Estados e ao Distrito Federal instituir impostos sobre: I - (omissis)

II - operações relativas à circulação de mercadorias e sobre prestações de serviços de transporte interestadual e intermunicipal e de comunicação, ainda que as operações e as prestações se iniciem no exterior;

A regulamentação sobre o assunto foi dada inicialmente pela Lei Complementar 87/1996, a chamada "Lei Kandir",, sofrendo diversas alterações e acréscimos pelas Leis

\footnotetext{
${ }^{4}$ A Lei Complementar 87/1996 é conhecida por "Lei Kandir" para homenagear o idealizador do texto legal, Antônio Kandir, ministro do Planejamento e Orçamento de 1996 a 1998, durante o governo de Fernando Henrique Cardoso.
} 
Complementares 92 de 23/12/1997, 99 de 20/12/1999, 102 de 11/07/2000, 114 de 16/12/2002, 115 de 26/12/2002, 120 de 29/12/2005 e 122 de 12/12/2006.

Por se tratar de imposto de competência dos Estados e do Distrito Federal, estes têm sua própria regulamentação acerca da cobrança do imposto, desde que, obviamente, respeitado o disposto nas Leis Complementares. O Rio Grande do Sul, por exemplo, trata o assunto através da Lei $n^{\circ} 8.820$ de 27/01/1989, do Decreto $n^{\circ} 37.699$ de 26/08/1997 e da Instrução Normativa do Departamento de Receita Pública Estadual n ${ }^{\circ}$ $45 / 1998$.

O ICMS é devido pelas pessoas físicas ou jurídicas (cadastradas ou não, registradas ou não, basta que se observe o intuito comercial) a que realizam operações descritas na Lei como fatores geradores do imposto, quais sejam: saída da mercadoria do estabelecimento comercial, industrial ou de produtor rural; início da prestação do serviço de transporte; prestação do serviço de comunicação; desembaraço aduaneiro das mercadorias importadas; e fornecimento de refeições ou de mercadorias com prestação de serviços.

Para entender como se calcula o valor do imposto devido, imperioso se faz entender o que é base de cálculo. Considerada o aspecto quantitativo do fato gerador, a base de cálculo pode ser definida como o quantum com o qual se determinará o montante devido pelo sujeito passivo ao fisco; compõe-se de, além do valor da mercadoria ou serviço, do valor do frete, do seguro, dos descontos condicionais, entre outros. É, muito em suma, o valor sobre o qual a alíquota será aplicada.

A Constituição Federal, no artigo referido alhures, define que cumpre aos Estados e ao Distrito Federal determinar a alíquota do imposto. Assim autorizado, o Estado do Rio Grande do Sul editou a Lei Estadual $n^{\circ} 8.820$ de 27/01/1989, cujos artigos 12 e 13 o fazem. Para este trabalho interessa a disposição do art. 12, II, "a" que institui a alíquota de $25 \%$ para as operações de prestação de serviços, inclusive o fornecimento de energia elétrica.

Ocorre que, seguindo uma tendência que datava da anterior Carta Magna, o valor do próprio tributo é considerado integrante da sua base de cálculo, conforme autorização expressa da Lei Complementar 87/96 (Art. 13, § $1^{\circ}, \mathrm{I}$ ). 
Art. 13. A base de cálculo do imposto é: (...) $\S 1^{\circ}$ Integra a base de cálculo do imposto, inclusive na hipótese do inciso V do caput deste artigo: (...) I - o montante do próprio imposto, constituindo o respectivo destaque mera indicação para fins de controle;

Esta determinação encontrou eco no art. 10 da Lei Estadual supracitada, da qual transcrevemos:

Art. 10. A base de cálculo do imposto é: (...) $\S 1^{\circ}$ Integra a base de cálculo do imposto, inclusive na hipótese do inciso V do "caput" deste artigo: (...) I o montante do próprio imposto, constituindo o respectivo destaque mera indicação para fins de controle;

Isso significa, na prática, que se um cidadão consumiu energia elétrica em valor igual a $\mathrm{R} \$ 100,00$ (cem reais), a alíquota de $25 \%$ faria com que o valor total a ser pago fosse de $\mathrm{R} \$ 125,00$ (cento e vinte e cinco reais). Entretanto não é o que ocorre, pois a alíquota será aplicada, em verdade, sobre aqueles hipotéticos R \$125,00 (cento e vinte e cinco reais), ou seja, sobre o valor do serviço mais o próprio imposto, resultando no pagamento total de $R \$ 131,25$ (cento e trinta e um reais e vinte e cinco centavos) - $R \$$ 100,00 (cem reais) referentes ao serviço prestado e $\mathrm{R} \$ 31,25$ (trinta e um reais e vinte e cinco centavos) constituindo o tributo, que é igual a 25\% de $\mathrm{R} \$ 125,00$ (cento e vinte e cinco reais), A esse expediente se dá o nome informal de "cobrança com base de cálculo por dentro"; assim será ela doravante nominada neste trabalho. Em outras palavras:

\begin{abstract}
A propósito, note-se, nesse passo, que se o ICMS exigido do contribuinte recai sobre o valor do produto ou serviço tributável, mas já agregado do mesmo imposto, vai daí que a alíquota estabelecida acaba incidindo então sobre uma base de cálculo já tributada. (...) Assim, é preciso (...) reconhecer que o chamado 'cálculo por dentro' nada mais representa mesmo do que fazer com que a alíquota do imposto incida por duas vezes no cálculo, uma sobre o preço e outra sobre este mesmo preço já tributado, uma manobra esperta e condenável, destinada a aumentar a arrecadação em prejuízo dos contribuintes. ${ }^{5}$ (Grifo nosso).
\end{abstract}

\title{
2. Recurso Extraordinário 212209-2
}

O Recurso Extraordinário 212.209-2 - RS levou à apreciação do Supremo Tribunal Federal, em meados de 1999, esse tema. O recorrente argumentou em suas

\footnotetext{
${ }^{5}$ TRIBUNAL DE ALÇADA CÍVEL DO ESTADO DE SÃO PAULO. Apelação Cível no 444.940/5, da $3^{a}$ Câmara do TA-CivSP, em 17/09/1991.
} 
razões recursais que tal ato - baseado na legislação do estado do Rio Grande do Sul viola os artigos $5^{\circ}$, XXII, $145 \S 1^{\circ}$ e 150 , IV, todos da Constituição Federal, discorrendo sobre o fato gerador do tributo e sua base de cálculo, a fim de demonstrar que este procedimento acarreta o aumento implícito deste imposto.

Com o fito de exemplificar o caso no corpo de seu voto, aduz o Ministro Marco Aurélio:

(...) as notas fiscais, relativas às operações de circulação de mercadorias consignam, em parcelas destacadas, o preço de venda e, considerada a percentagem a incidir sobre este, a quantia devida pelo vendedor (contribuinte de direito) ao fisco a título de Imposto de Circulação de Mercadorias. Pois bem, em que pese a este destaque, iniludivelmente o meio de controle do recolhimento do tributo, passou o fisco - a mercê, é fato, de norma de estatura superior a local, no que este repetiu preceito de diploma abrangente e aplicável em todo território nacional - a exigir do vendedor não o recolhimento do valor decorrente da incidência da alíquota, sobre o preço do negócio mercantil, mas o resultante do somatório das parcelas, criando-se, assim, uma segunda base de cálculo estranha $(. . .)^{6}$

O Ministro posicionou-se defendendo a inconstitucionalidade da base de cálculo "por dentro". Cita, fundamentando sua posição, os ensinamentos de Roque Carrazza:

Deveras, a Lei Complementar ao estabelecer que a base de cálculo do ICMS corresponde ao valor da operação ou prestação somado ao próprio tributo, extrapolou os limites constitucionais, ferindo a regra-matriz do tributo, determinou, por meio deste estratagema, a cobrança de ICMS sobre grandezas estranhas à materialidade de sua hipótese de incidência. ${ }^{7}$

Prossegue o citado tributarista dizendo que:

Se o imposto é sobre operações mercantis, sua base de cálculo só pode ser o valor da operação mercantil realizada. Se o imposto é sobre prestações de serviços de transporte transmunicipal ou de comunicações, sua base de cálculo só pode ser o preço do serviço prestado. ${ }^{8}$

Por este motivo, concluiu o Ministro Marco Aurélio que foi desrespeitado o preceito do art. $145, \S 1^{\circ}, \mathrm{CF}$, que "revela como razão de ser do tributo a capacidade econômica do contribuinte"; que o "tributo não pode extravasar, dada a alíquota e a base de cálculo, o valor, em si, da operação", o que se verifica no caso em tela, ou seja, a transgressão o art. 155, II, CF; alertou para a impossibilidade de se obedecer a nãocumulatividade do art. $155, \S 2^{\circ}$, I, "se se chega ao cálculo englobado"; e, por fim,

\footnotetext{
${ }^{6}$ SUPREMO TRIBUNAL FEDERAL. Recurso Extraordinário n 212209-2. p. 6.

${ }^{7}$ CARRAZZA, Roque Antonio. ICMS. $8^{\mathrm{a}}$ ed. São Paulo: Malheiros, 2002. p. 210.

${ }^{8}$ Idem
} 
olvidou da legalidade estrita dos tributos, pois a alíquota não deve nem pode sofrer acréscimos, mesmo que sutis, como o do caso apresentado.

Seu entendimento não foi acompanhado, entretanto, pelos demais Ministros, que decidiram por conhecer o recurso, mas não lhe dar provimento; embasaram esta decisão nos argumentos referidos a seguir, expostos pelo Min. Nelson Jobim:

1) $\mathrm{O}$ texto do $\S 7^{\circ}$ do art. $2^{\circ}$ do Decreto-Lei 406 de 31 de dezembro de $1968-$ editado pelo então Presidente da República Costa e Silva que se utilizou das atribuições contidas no Ato Institucional $\mathrm{n}^{\circ} 5$ - expressa que:

Art $2^{\circ}$. A base de cálculo do impôsto é: (...) $§ 7^{\circ} \mathrm{O}$ montante do impôsto de circulação de mercadorias integra a base de cálculo a que se refere êste artigo, constituindo o respectivo destaque mera indicação para fins de contrôle.

2) A LC $87 / 96$ traz semelhante dispositivo em seu art. $13, \S 1^{\circ}$, I;

3) Demonstrando através de um exemplo a impossibilidade, em seu ver, de dissociar o imposto da sua base de cálculo a cada incidência do mesmo e as conseqüências no mundo prático de tal ato.

\section{Emenda Constitucional $n^{\circ} 33$ de 11/12/2001}

Visando a soterrar as muitas discussões acerca da constitucionalidade ou não da base de cálculo "por dentro", aproveitando a posição favorável do STF acerca do instituto, aprovou-se a Emenda Constitucional de n 33, em 11 de dezembro de 2001, que inseriu a alínea “i” no inciso XII do $\S 2^{\circ}$ do artigo 155 da Constituição Federal, com a seguinte redação:

Art. 155. Compete aos Estados e ao Distrito Federal instituir impostos sobre: (...) II - operações relativas à circulação de mercadorias e sobre prestações de serviços de transporte interestadual e intermunicipal e de comunicação, ainda que as operações e as prestações se iniciem no exterior; (...) $\S 2 .^{\circ} \mathrm{O}$ imposto previsto no inciso II atenderá ao seguinte: (...) XII - cabe à lei complementar: (...) i) fixar a base de cálculo, de modo que o montante do imposto a integre, também na importação do exterior de bem, mercadoria ou serviço. (Grifo nosso). 
Como se vê, intentou-se assim "convalidar, por via reflexa (com a cândida frase 'também na importação do exterior de bem, mercadoria ou serviço'), o cálculo por dentro do ICMS". 9 Esse recurso, entretanto, não teve o condão de dar um fim à insatisfação, nem, em nossa visão, de expurgar a inconstitucionalidade presente nesse método de cálculo, como se verá. Assim, prosseguiram as contestações judiciais à base de cálculo do ICMS, das quais destacamos o Processo n ${ }^{\circ}$ 27/1.05.0013489-0.

\section{Processo de $n^{\circ}$ 027/1.05.0013489-0:}

Em 05 de fevereiro de 2003, a Associação de Proteção e Defesa do Consumidor de Santa Maria ajuizou, em face do Estado do Rio Grande do Sul e da AES Sul Distribuidora Gaúcha de Energia, uma Ação Civil Pública alegando também a inconstitucionalidade da base de cálculo "por dentro" do ICMS, e pedindo a proibição de sua aplicação sobre o fornecimento de energia elétrica. Após concluir pela ilegitimidade passiva da AES Sul, mera concessionária do serviço, sem poder de decisão sobre quais tributos incidiriam sobre ele, o magistrado Vanderlei Deolindo, titular da $2^{\text {a }}$ Vara Cível da Comarca de Santa Maria, passou a analisar o mérito da questão.

Inicialmente aduz que: "Não se pode, por meio de interpretações nebulosas, procurar justificar que $25 \%$ sobre $\mathrm{R} \$ 100,00$ não é $\mathrm{R} \$ 25,00$ e sim $\mathrm{R} \$ 33,00$. Constituise uma afronta à matemática, ciência exata que não permite esse tipo de raciocínio." ${ }^{10} \mathrm{~A}$ partir desse raciocínio, o citado julgador entendeu que a cobrança "por dentro" é uma "afronta ao Direito do Consumidor"11, mesmo após a Emenda Constitucional de n ${ }^{\mathrm{o}} 33$, pois ela permitiu que "o legislador estadual majorasse as alíquotas do ICMS, sendo que as alíquotas máximas deste tributo devem ser fixadas por resolução do Senado". ${ }^{12}$

\footnotetext{
${ }^{9}$ Ibidem, p. 220.

10 TRIBUnAl DE JUSTiÇA DO ESTADO DO RIO GRANDE DO SUl. Processo $\mathbf{n}^{\circ}$ 027/1.05.0013489-0, Segunda Vara Cível, 2005.

${ }^{11}$ Idem.

${ }^{12}$ Idem.
} 
Ainda segundo Deolindo, “a sistemática do cálculo pertinente à base de cálculo do ICMS confere a este tributo o 'efeito cascata', ferindo o princípio da nãocumulatividade, tornando-o inconstitucional". ${ }^{13} \mathrm{O}$ feito, entretanto, foi extinto em segunda instância, em decorrência de um vício formal - o Tribunal entendeu que a Ação Civil Pública não é meio adequado para a discussão de tributos. ${ }^{14}$

Não obstante, entendemos irreprochável a análise do juiz monocrático em relação ao mérito da lide. Passaremos, então, a demonstrar porque a base de cálculo "por dentro" ofende não só a matemática, mas também a ordem jurídica e constitucional vigente, mesmo após o advento da EC 33/01.

\title{
5. Da inconstitucionalidade da base de cálculo "por dentro" do ICMS
}

Como explanado anteriormente, todo tributo possui um fato gerador. Conforme explica José Cretella Júnior:

\begin{abstract}
Na realidade, fato gerador é o que os cultores da filosofia denominam de causa, 'aquilo em virtude do que algo existe'. Também de 'fato imponível', 'fato tributo', 'hipótese de incidência', 'suporte fático', 'situação base', a expressão equivale ao vocábulo italiano fattispecie e ao alemão Tatbbestand. (...) Fato gerador ou fato jurígeno do imposto é o evento - fato ou ato - que independendo de qualquer iniciativa ou participação do Estado, é da responsabilidade única do contribuinte, em razão de sua titularidade ou de ato por ele praticado. ${ }^{15}$
\end{abstract}

Também a base de cálculo, descrita alhures como "aspecto quantitativo do tributo", exerce função essencial na definição jurídica da natureza do tributo; é necessário que seja compatível com o fato gerador, com ela mantendo correlação lógica. Conforme Carrazza:

Melhor esclarecendo, se o tributo é sobre a renda, sua base de cálculo deverá, necessariamente, levar em conta a medida da renda ('v.g.', a renda líquida); se o tributo é sobre a propriedade, sua base de cálculo devera, necessariamente, levar em conta uma medida da propriedade ('v.g.', valor venal da propriedade); se o tributo é sobre serviços, sua base de cálculo

\footnotetext{
${ }^{13}$ Idem.

14 TRIBUnAL DE JUSTIÇA DO ESTADO DO RIO GRANDE DO SUL. Apelação Cível no 70015703176, Vigésima Segunda Câmara Cível, 2006.

15 CRETElla JÚNIOR, José. Curso de Direito Tributário constitucional. $2^{\mathrm{a}}$ ed. Rio de Janeiro: Forense Universitária, 1999. p. 23
} 
deverá, necessariamente, levar em conta uma medida dos serviços ('v.g.', o valor dos serviços prestados), e assim por diante. ${ }^{16}$

Isso esclarecido, sabe-se que a hipótese de incidência do ICMS, conforme explicitado no primeiro item deste trabalho, são "operações relativas à circulação de mercadorias e sobre prestações de serviços de transporte interestadual e intermunicipal e de comunicação, ainda que as operações e as prestações se iniciem no exterior". ${ }^{17}$

Ora, se a base de cálculo do ICMS passa a incluir o valor do próprio tributo, então o que se está tributando não é tão-somente a prestação de serviços e a circulação de mercadorias, mas também o próprio ato de tributar. E isso constitui teratologia incompatível não apenas com a própria definição de fato gerador (pois este deve, obrigatoriamente, consubstanciar-se em ato de particular, conforme notado por Cretella Júnior, e o ato de tributar é exclusivo do Poder Público), mas também com o fato gerador do ICMS. $^{18}$

Assim, fica evidente a ofensa ao artigo 145, II, da Constituição Federal, que as hipóteses de incidência desse tributo. Sobre essa necessária correlação entre base de cálculo e fato gerador, sem a qual se desnatura o tributo, afirma Rubens Gomes de Sousa:

Se um tributo formalmente instituído como incidindo sobre determinado pressuposto de fato ou de direito, é calculado com base em uma circunstância estranha a esse pressuposto, é evidente que não se poderá admitir que a natureza jurídica desse tributo seja a que normalmente corresponderia à definição de sua incidência. Assim, um imposto sobre vendas e consignações, mas calculado sobre o capital da firma, ou sobre o valor de seu estoque, em vez de o ser sobre o preço da mercadoria vendida ou consignada, claramente não seria um imposto de vendas e consignações, mas um imposto sobre o capital ou sobre o patrimônio. ${ }^{19}$

A partir dessas considerações, Carrazza conclui, em consonância com o afirmado:

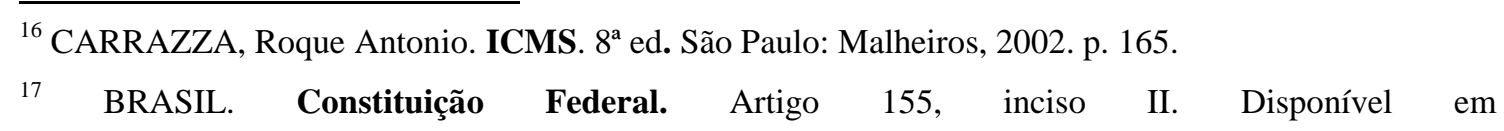
<http://www.planalto.gov.br/ccivil_03/constituicao/constituiçao.htm>. Acesso em 15 de julho de 2009.

${ }^{18}$ Isso conforme o artigo 145 da Constituição Federal, que outorga exclusivamente à União, aos EstadosMembros, ao Distrito Federal e aos Municípios o poder de instituir (e, por conseguinte, cobrar) impostos, taxas e contribuições de melhoria.

${ }^{19}$ SOUSA, Rubens Gomes apud CARRAZZA, Roque Antonio, ibidem, p. 205. 


\begin{abstract}
Depreende-se que a manipulação da base de cálculo do tributo acaba fatalmente alterando sua regra-matriz constitucional, deixando o contribuinte sob o império da insegurança. Com efeito, mudando-se a base de cálculo possível do tributo, fatalmente acaba-se por instituir exação diversa daquela que a pessoa política é competente para criar, nos termos da Carta Suprema. Em síntese, descaracterizada a base de cálculo, descaracterizado também estará o tributo. Não é por outra razão que o divórcio entre a hipótese de incidência e a base de cálculo do tributo causa irremissível inconstitucionalidade. A desvinculação entre ambas distorce o sistema tributário. (...) Transplantando essas noções, apenas bosquejadas, para o ponto que faz aqui nossos cuidados, temos que, embora a Constituição não aponte a base de cálculo do ICMS (como, de resto, não aponta a base de cálculo de nenhum tributo), ela implicitamente dá diretrizes acerca do assunto, que nem o legislador, nem o intérprete, podem ignorar. ${ }^{20}$
\end{abstract}

Apesar disso, o então Ministro Nelson Jobim, defendendo a base de cálculo "por dentro", usou de analogia com o "efeito cascata" em relação aos demais impostos. Este efeito faz com que a incidência de um tributo em determinada operação influa naquelas que dela dependerem (a tributação sobre a energia elétrica utilizada na produção de um bem de consumo influirá em seu preço, que influirá na tributação sobre a circulação dessa mercadoria, por exemplo) ${ }^{21}$. Trata-se, entretanto, de raciocínio falacioso e deslocado do objeto de discussão.

Isso porque o fato de um determinado tributo influir no preço do bem ou serviço não desnatura a hipótese de incidência do ICMS; diga-se: se o preço de uma mercadoria varia conforme a tributação incidente sobre a sua produção (além de outros muitos fatores: custo da matéria prima, da mão de obra etc.), o ICMS ainda estará sendo calculado sobre o valor venal da coisa (que agrega os muitos custos citados, inclusive tributários), de acordo com o fato gerador, e não sobre dois valores diversos: o valor venal da coisa e o valor do tributo que futuramente incidirá sobre ela. São muito diferentes os "efeitos cascata" aquele em que um tributo incide sobre si mesmo, e aquele em que o tributo influi no preço do bem, que influirá em outro tributo.

Assim sendo, forçoso concluir pela insanável inconstitucionalidade da base de cálculo "por dentro" do ICMS. Nem mesmo a Emenda Constitucional de no 33 , de 2001, editada para dar um verniz constitucional à prática, tem o condão de legitimá-la; pelo contrário, obrou apenas introduzir antinomia inconciliável no âmbito das normas constitucionais. E isso não pode ser permitido, pois o poder constituinte derivado deve

\footnotetext{
${ }^{20}$ CARRAZZA, Roque Antonio. Ibdem. p. 176.

${ }^{21}$ SUPREMO TRIBUNAL FEDERAL. Recurso Extraordinário n ${ }^{\circ}$ 212209-2, 1999.
} 
obediência aos preceitos firmados pelo poder constituinte originário. A isso ilustra Pedro Lenza:

O poder constituinte derivado é também denominado instituído, constituído, secundário, de segundo grau. Como o próprio nome sugere, o poder constituinte derivado é criado e instituído pelo originário. Assim, ao contrário de seu "criador", que é ilimitado, incondicionado, inicial, o derivado deve obedecer às regras colocadas e impostas pelo originário, sendo, nesse sentido, limitado e condicionado aos parâmetros a ele impostos. ${ }^{22}$

Por tal motivo, é vedado que o legislador, por emenda constitucional, introduza antinomia na Carta Magna, em desrespeito ao princípio supremo da unidade da Constituição, como fez a Emenda Constitucional de no 33/01, oposta à ordem tributária instituída (e a uma miríade de artigos constitucionais). Conforme anota Canotilho:

O princípio da unidade obriga o intérprete a considerar a constituição na sua
globalidade e a procurar harmonizar os espaços de tensão (...) existentes entre
as normas constitucionais a concretizar (ex.: princípio do Estado
Democrático de Direito e princípio democrático, princípio unitário e
princípio da autonomia regional e local).

Logo, existe limitação material implícita ${ }^{24}$ a poder de reforma constitucional que impede a positivação da base de cálculo "por dentro", pois fere uma série de direitos constitucionais fundamentais. Máxime entre eles está o direito do contribuinte de ser tributado na forma e nos limites contidos na Constituição.

Exemplificativamente, também foi vulnerado o inciso II do artigo 155, que prevê as hipóteses de incidência do ICMS. Outra norma espezinhada pela Emenda Constitucional foi o $\S 2^{\circ}$, incisos IV e V, do mesmo artigo da Constituição Federal, que confere ao Senado Federal o poder de fixar, por resolução, as alíquotas máximas do ICMS. A sobredita emenda conferiu às leis complementares e estaduais o poder de aumentar, por via oblíqua, a alíquota efetiva do referido imposto, mesmo além dos parâmetros do Senado (atualmente constantes da Resolução de nº 22/89).

Vejamos: no exemplo citado neste trabalho, notamos que a alíquota efetiva incidente sobre o fornecimento de energia elétrica não é de $25 \%$ (vinte e cinco por cento), como institui a Lei Estadual n $\mathrm{n}^{\circ} 8.820 / 89$, mas de $25 \%$ (vinte e cinco por cento)

\footnotetext{
${ }^{22}$ LENZA, Pedro. Direito Constitucional Esquematizado. 12a ed. São Paulo: Saraiva, 2008. p. 86.

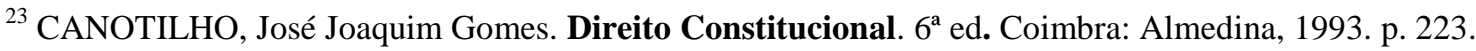

${ }^{24}$ SILVA, José Afonso. Direito Constitucional Positivo. $27^{\mathrm{a}}$ ed. São Paulo: Malheiros, 2006. p. 65.
} 
sobre $125 \%$ (cento e vinte e cinco por cento) do valor do serviço, ou seja, 31,25\% (trinta e um e vinte e cinco centésimos por cento). Ou seja, calculando "por dentro", o Estado está, em verdade, majorando a alíquota através de um obscuro artifício, mesmo em desrespeito ao teto fixado pelas resoluções que guiam a matéria - garantia inarredável do contribuinte. Carrazzo, em análise da matéria, conclui o seguinte:

\begin{abstract}
Como já vimos, tal determinação é inconstitucional, porque não rima com a regra-matriz do ICMS e, o que é pior, compele o contribuinte a pagar um tributo confiscatório, que não leva em conta sua capacidade econômica. (...) Se a Carta Magna não contempla esta hipótese de imposto incidente sobre imposto, de forma alguma o legislador (...) poderia tê-lo instituído, ainda que fazendo-o integrar sua própria base de cálculo. Ademais, a 'fórmula' encontrada pela legislação no pertinente à base de cálculo do ICMS confere a este tributo o 'feito cascata', ferindo, deste modo, o princípio da nãocumulatividade. Finalmente, tal 'fórmula' leva a uma majoração indevida de alíquotas, costeando os preceitos previstos nas resoluções do Senado que cuidam da matéria. (...) $\mathrm{O}$ 'cálculo por dentro' leva à quebra da alíquota geral, em favor da alíquota real, majorada sem lei e sem observância dos tetos fixados em resoluções do Senado. (...) A Emenda Constitucional 33/2001 acrescentou uma alínea $i$ ao art. 155, $\S 2^{\circ}$, XII, da Carta Magna, autorizando a lei complementar a 'fixar a base de cálculo (do ICMS) de modo que o montante do imposto a integre também na importação do exterior de bem, mercadoria ou serviço". Tentou-se, assim, convalidar, por via reflexa (com a cândida frase "integre também na importação do exterior de bem, mercadoria ou serviço'), o cálculo por dentro do ICMS, que aqui estamos zurzindo. Esta manobra capciosa, no entanto, não anula o capítulo que acabamos de escrever. Com efeito, não é dado ao poder constituinte derivado alterar a regra-matriz constitucional de tributo algum, modificando-lhe arbitrariamente - como no caso em estudo - a base de cálculo possível.
\end{abstract}

\title{
Considerações finais
}

Ante o exposto, percebe-se que a cobrança "por dentro" - reiterado hábito legitimado por via oblíqua com fulcro na EC 33/2001 - é inconstitucional. Inconcebível seria aceitar que o Poder Constituinte Derivado alterasse de forma indireta, mas com resultados substanciais, o que o Poder Constituinte Originário já regulamentou sem deixar lacunas.

Tal atitude estarrece juristas e doutrinadores, a exemplo de Roque Carazza e Sacha Coêlho, uma vez que entre o choque da legislação infraconstitucional e a Constituição, aquela mostra-se superior, trazendo, certamente, insegurança jurídica a todos. Ao conferir ao Estado o poder de tributar duplamente, o método trazido pela legislação infraconstitucional, no que tange a base de cálculo do ICMS, golpeia o princípio constitucional da não-cumulatividade. O fato de ser uma fórmula ardilosa de 
aumento da alíquota fere ainda a razão de ser dos tributos apresentada pela Carta Magna no art. $145, \S 1^{\circ}$, qual seja, a capacidade econômica do contribuinte.

Nesse sentido, a cobrança "por dentro", além de descumprir o disposto no texto constitucional, desrespeita o teto fixado pelas Resoluções do Senado, pois esse procedimento nada mais é do que um meio sutil de aumentar a arrecadação do imposto. A edição da EC 33/2001 e as decisões contrárias apresentadas neste trabalho não anulam nosso posicionamento, apenas reforçam nossas convicções, pois não é possível admitir que o texto constitucional seja alterado e interpretado de forma a prejudicar aqueles a quem se propõe a beneficiar. 


\section{REFERÊNCIAS BIBLIOGRÁFICAS}

BRASIL. Constituição $\quad$ Federal. $\quad$ Disponível em <http://www.planalto.gov.br/ccivil_03/constituicao/constituiçao.htm>. Acesso em 15 de julho de 2009.

CANOTILHO, José Joaquim Gomes. Direito Constitucional. 6ª ed. Coimbra: Almedina, 1993.

CARRAZZA, Roque Antonio. ICMS. $8^{\text {a }}$ ed. São Paulo: Malheiros, 2002.

COÊLHO, Sacha Calmon Navarro. Curso de Direito Tributário Brasileiro. $9^{a}$ Ed. Rio de Janeiro: Forense, 2006.

CRETElla JÚNIOR, José. Curso de Direito Tributário Constitucional. $2^{\mathrm{a}}$ ed. Rio de Janeiro: Forense Universitária, 1999.

FROSSARD, Dermeval. Considerações sobre a base de cálculo do ICMS. Disponível em $\langle$ http://www.editoraferreira.com.br/publique/media/dermeval_toq1.pdf $>$. Acessado em 28.03.2009

GRINOVER, Ada Pellegrini [ et $a$ al. $]$. Código Brasileiro de Defesa do Consumidor: comentado pelos autores do anteprojeto. $8^{\mathrm{a}}$ ed. Rio de Janeiro: Forense Universitária, 2005.

LENZA, Pedro. Direito Constitucional Esquematizado. 12a ed. São Paulo: Saraiva, 2008.

SILVA, José Afonso. Direito Constitucional Positivo. 27ª ed. São Paulo: Malheiros, 2006.

SUPREMO TRIBUNAL FEDERAL. Recurso Extraordinário n 212209-2, 1999.

TRIBUNAL DE ALÇADA CÍVEL DO ESTADO DE SÃO PAULO. Apelação Cível no 444.940/5, da 3 ${ }^{\text {a }}$ Câmara do TA-CivSP, em 17/09/1991.

TRIBUNAL DE JUSTIÇA DO ESTADO DO RIO GRANDE DO SUL. Processo $\mathbf{n}^{\circ}$ 027/1.05.0013489-0, Segunda Vara Cível, 2005.

TRIBUNAL DE JUSTIÇA DO ESTADO DO RIO GRANDE DO SUL. Apelação Cível $\mathbf{n}^{\circ}$ 70015703176,Vigésima Segunda Câmara Cìvel, 2006. 